\title{
FUZZY INFERENCE SYTEM TSUKAMOTO UNTUK PENENTUAN PENERIMA JAMKESMAS DENGAN MICROSOFT VISUAL BASIC DAN MYSQL
}

\author{
M. Ghofar Rohman \\ Dosen Program Studi Teknik Informatika, Fakultas Teknik,Universitas Islam Lamongan \\ Jl. Veteran No. 53 A Lamongan \\ Telp. (0322) 324706 \\ E-mail: ghofar.kit@gmail.com
}

\begin{abstract}
The problem that existed in the health service agency in this case is the health center, namely the determination of the recipient of public health insurance (Jamkesmas), although in practice the determination of recipients Jamkesmas already using the computer, but only limited to the support and there is no system that can be used to support the retrieval Decisions based on existing variables. The decision support system for determining the members of Jamkesmas recipients, where the system is used to help determine the recipients of Jamkesmas to be provided in accordance with their respective groups to accelerate the work of determining the provision of Jamkesmas. The system can assist the puskesmas in determining the members of Jamkesmas beneficiaries in accordance with the appropriate class to the community who want to become the members of Jamkesmas beneficiaries at the Puskesmas. This decision support system using the Fuzzy Tsukamoto Method, which will provide a decision solution to the puskesmas in determining the members of the public health insurance (Jamkesmas).
\end{abstract}

Keywords: SMEs, e-commerce, marketing, information technology.

\section{PENDAHULUAN}

Pada Undang-Undang Dasar 1945 Pasal 28 dan Undang-Undang No. 23 Tahun 1992 tentang kesehatan menetapkan bahwa setiap orang berhak mendapatkan pelayanan kesehatan. Untuk menjamin akses penduduk miskin terhadap pelayanan kesehatan sebagaimana diamanatkan dalam UUD 1945 tersebut, pemerintah telah berupaya untuk membuat kebijakan melalui Program Jaminan Kesehatan Masyarakat (Jamkesmas). Program Jamkesmas dilaksanakan di hampir semua rumah sakit pemerintah di Indonesia. Pelaksanaan Program Jamkesmas berdasarkan pada Keputusan Menteri Kesehatan RI No. 125/Menkes/SK/II/ Tahun 2008 tentang Pedoman Penyelenggaraan Program Kesehatan Masyarakat. Dalam menentukan penerima Jamkesmas pada umumnya telah menggunakan bantuan komputer, tetapi penggunaanya belum optimal. Hal ini menyebabkan pengelolaan data Jamkesmas yang tidak efisien terutama dari segi waktu dan banyaknya perulangan proses yang sebenarnya dapat diefisienkan. Oleh karena itu, perlu adanya suatu sistem yang mendukung proses penentuan penerima Jamkesmas, sehingga dapat mempersingkat waktu penyeleksian dan dapat meningkatkan kualitas keputusan dalam menentukan penerima Jamkesmas.

Model yang digunakan dalam aplikasi sistem pengambilan keputusan ini adalah dengan menggunakan metode logika fuzzy tsukamoto. Metode ini dipilih karena metode ini menentukan nilai bobot untuk setiap atribut, kemudian dilanjutkan dengan proses perankingan yang akan menyeleksi alternatif terbaik dari sejumlah alternatif, dalam hal ini alternatif yang dimaksud adalah yang berhak menerima jamkesmas berdasarkan kriteriakriteria yang ditentukan. Dengan demikian, diharapkan penilaian akan lebih tepat karena didasarkan pada nilai kriteria dan bobot yang sudah ditentukan sehingga akan mendapatkan hasil yang lebih akurat terhadap siapa yang akan menerima beasiswa tersebut. Hasil keputusan yang telah diambil tersebut dapat memberikan sesuatu yang benar-benar berharga dan bermanfaat bagi para masyarakat yang berhak untuk mendapatkan jamkesmas tersebut.

Penelitian menggunakan Metode Fuzzy Tsukamoto pernah dilakukan oleh Ihsan (2012). Dalam penelitian tersebut Metode Fuzzy Tsukamoto digunakan untuk menentukan penerimaan nominal beasiswa. Hasil dari penelitian tersebut dapat membatu proses 
penentuan besar nominal beasiswa dengan akurat.

Penelitian menggunakan Metode Fuzzy Tsukamoto juga pernah dilakukan oleh Farouq (2014) untuk penilaian calon pegawai yang akan melakukan test kenaikan jabatan. Hasil dari penelitian tersebut Metode Fuzzy Tsukamoto dapat di implementasikan dengan baik pada java dan dapat membantu proses pengambilan keputusan yang akurat.

Oleh karena itu, dibutuhkan suatu sistem pendukung keputusan yang nantinya akan membantu dalam proses pengambilan keputusan dalam menentukan penerima atau peserta jamkesmas. Berdasarkan uraian di atas, maka penulis mengambil topik untuk menyusun penelitian ini dengan judul "Fuzzy Inference Sytem Tsukamoto Untuk Penentuan Penerima Jamkesmas dengan Microsoft Visual Basic dan MySQL".

Decision Support System atau dalam bahasa Indonesia Sistem Pendukung Keputusan yang disingkat SPK menurut beberapa ahli dijelaskan sebagai berikut (Turban, Dkk. 2005): Sistem Pendukung Keputusan merupakan suatu sistem interaktif, yang membantu pengambil keputusan melalui penggunaan data dan modelmodel keputusan untuk memecahkan masalahmasalah yang sifatnya semi terstruktur dan tidak terstruktur.

Menurut Maryan Alavi dan H.Albert Napier Sistem Pendukung Keputusan merupakan suatu kumpulan prosedur pemrosesan data dan informasi yang berorientasi pada penggunaan model untuk menghasilkan berbagai jawaban yang dapat membantu manajemen dalam pengambilan keputusan. Sistem ini harus sederhana, mudah dan adaptif.

Menurut Little Sistem Pendukung Keputusan adalah suatu sistem informasi berbasis komputer yang menghasilkan berbagai alternatif keputusan untuk membantu manajemen dalam menangani berbagai permasalahan yang terstruktur ataupun tidak terstruktur dengan menggunakan data dan model.

Menurut Raymond McLeod, Jr. Sistem Pendukung Keputusan merupakan sistem informasi spesifik yang dutujukan untuk memecahkan suatu masalah tertentu yang harus dipecahkan oleh manager pada berbagai tingkatan.

Dari berbagai pengertian akan Sistem Pendukung Keputusan di atas maka dapat ditarik sebuah kesimpulan Sistem Pendukung Keputusan adalah sebuah sistem yang digunakan dalam membantu memecahkan permasalahan atau membantu dalam mencari solusi dari permasalahan berdasarkan data yang ada dan model yang sesuai.

Konsep logika fuzzy pertama kali diperkenalkan oleh professor Lotfi A. Zadeh dari Universitas California, pada bulan Juni 1965. Logika fuzzy merupakan generalisasi dari logikaklasik yang hanya memiliki dua nilai keanggotaan yaitu 0 dan 1. Dalam logika fuzzy, nilaikebenaran suatu pernyataan berkisar dari sepenuhnya benar sampai dengan sepenuhnya salah. Dengan teori himpunan fuzzy, suatu objek dapat menjadi anggota dari banyak himpunandengan derajat keanggotaan yang berbeda dalam masing-masing himpunan. Konsep ini berbeda dengan teori himpunan biner (crisp). Teori himpunan biner tergantung pada logika dua-nilai (two-valued logic) untuk menentukan apakah sebuah objek merupakan suatu anggotahimpunan atau bukan (Klir \& Bo, 1995).

Himpunan fuzzy memiliki 2 atribut, yaitu (Kusumadewi,2004):

Linguistik, penamaan suatu grup yang mewakili suatu keadaan atau kondisi tertentu dengan menggunakan bahasa alami, seperti: dingin,sejuk,normal,hangat,panas.

Numeris, suatu nilai (angka) yang menunjukkan ukuran dari suatu variabel, seperti: $0,1,2,3,4$, dst.

Ada beberapa hal yang perlu diketahui dalam memahami sistem fuzzy, yaitu : variabel fuzzy,himpunan fuzzy, semesta pembicaraan, dan domain. Fungsi keanggotaan (membership function) adalah suatu kurva yang menunjukkan pemetaan titik-titik input data ke dalam nilai keanggotaannya yang memiliki interval antara 0 sampai 1 (Kusumadewi \& Hari, 2004)

Dalam membangun sebuah sistem fuzzy dikenal beberapa metode penalaran, antara lain : metode Tsukamoto, metode Mamdani dan metode Sugeno. Pada metode Tsukamoto, setiap konsekuen pada aturan berbentuk IF-THEN harus direpresentasikan dengan suatu himpunan fuzzy dengan fungsi keanggotaan monoton. Sebagai hasilnya, output hasil inferensi dari tiap-tiap aturan diberikan dengan tegas (crisp) berdasarkan $\alpha$ predikat (fire strength). Hasil akhirnya diperoleh dengan menggunakan rata-rata terbobot. Misal ada 2 variabel input, var- 
1(x) dan var-2(y) serta 1 variabel output var-3(z), di mana var-1 terbagi atas 2 himpunan yaitu A1 dan A2 dan var-2 terbagi atas himpunan B1 dan B2. Sedangkan var-3 juga terbagi atas 2 himpunan yaitu $\mathrm{C} 1$ dan C2. (Kusumadewi dalam Ariani dan Endra. 2013)

Pelaksanaan Program Jamkesmas berdasarkan pada Keputusan Menteri Kesehatan RI No. 125/Menkes/SK/II/2008 tentang Pedoman Penyelenggaraan Program Kesehatan Masyarakat Tahun 2008 tanggal 6 Februari 2008 Tujuan Penyelenggaraan Program Jamkesmas secara umum adalah untuk memberikan akselerasi dalam peningkatan akses dan mutu pelayanan kesehatan terhadap seluruh masyarakat miskin dan tidak mampu agar tercapai derajat kesehatan masyarakat yang optimal secara efektif dan efisien. Secara khusus program Jamkesmas ditujukan untuk meningkatkan cakupan masyarakat miskin dan tidak mampu guna mendapat pelayanan kesehatan di Puskesmas serta jaringannya dan di Rumah Sakit. Melalui program Jamkesmas pula diharapkan akan terjadi proses penyelenggaraan pengelolaan keuangan yang transparan dan akuntabel yang pada akhirnya akan berdampak kepada peningkatan kualitas pelayanan kesehatan bagi masyarakat miskin (Departemen kesehatan RI. 2008:5).

Program Jamkesmas memberikan pelindungan sosial di bidang kesehatan untuk menjamin masyarakat miskin dan tidak mampu yang iurannya dibayar oleh pemerintah agar kebutuhan dasar kesehatannya yang layak dapat terpenuhi. Iuran bagi masyarakat miskin dan tidak mampu dalam program Jamkesmas bersumber dari Anggaran Pengeluaran dan Belanja Negara (APBN) dari Mata Anggaran Kegiatan (MAK) belanja bantuan sosial. Pada hakikatnya pelayanan kesehatan terhadap peserta menjadi tanggung jawab dan dilaksanakan bersama oleh Pemerintah Pusat dan Pemerintah Daerah. Pemerintah Daerah Provinsi/Kabupaten/Kota berkewajiban memberikan kontribusi sehingga menghasilkan pelayanan yang optimal (Departemen kesehatan RI. 2011: 7).

Program Jamkesmas berbentuk bantuan sosial untuk pelayanan kesehatan bagi masyarakat miskin dan tidak mampu dan diselenggarakan secara nasional agar terjadi subsidi silang dalam rangka mewujudkan pelayanan kesehatan yang menyeluruh bagi masyarakat miskin. Kegiatan yang dilaksanakan dalam Program Jamkesmas meliputi (1) pembinaan, pengembangan pembiayaan dan jaminan pemeliharaan kesehatan, (2) pelayanan kesehatan rujukan bagi masyarakat miskin, dan (3) pelayanan kesehatan dasar bagi masyarakat miskin (Ahdiyana dan Wasiti. 2013).

\section{METODE PENELITIAN}

Permasalahan yang ada pada puskesmas diantaranya adalah pengerjaan penentuan pemberian jamkesmas yang masih manual, sehingga memiliki tingkat kecepatan dan keakuratan data yang kurang valid yang menyebabkan kesalahan saat penulisan maupun penentuan pengambilan keputusan pemberian jamkesmas. Serta tidak adanya database kriteria penerima yang ingin mendapatkan jaminan kesehatan masyarakat. Selain itu selama ini masih mengandalkan media kertas dan brankas file untuk menyiman file data-datanya.

Setelah menganalisis permasalahan tersebut dapat disimpulkan bahwa dibutuhkan aplikasi yang dapat mengurangi permasalahan yang ada, selain itu aplikasi juga digunakan untuk mengontrol banyaknya pengajuan jaminan kesehatan sehingga jika ada kekeliruan saat pendataan maka bisa langsung diperbaiki kesalahan yang ada.

Setelah melakukan proses tanya jawab dengan pegawai yang sedang bertugas, maka penulis menyimpulkan informasi yang dibutuhkan dari Sistem Pendukung Keputusan Penentuan Pemberian Jamkesmas antara lain:

1) Laporan data penerima jamkesmas.

2) Alur proses penentuan pemberian jamkesmas.

3) Data penerima jamkesmas.

4) Data user / pengguna.

Menguraikan konsep pemodelan sistem dan alasan kenapa pemodelan sistem perlu dilakukan. Pada perancangan proses ini menjelaskan tentang desain arsitektur yang dibuat dalam perancangan dan pembuatan program yakni use case diagram, activity diagram serta sequence diagram.

Gambar 1 adalah use case diagram yang menerangkan proses yang bisa diakses oleh admin, yaitu menu login, menu file, menu pencarian dan menu about. Pada menu login terdapat menu utama yang berisi menu kriteria, menu nilai, dan menu penentuan. Pada menu 
file terdapat report data kriteria, report data nilai, dan report data hasil. Selain itu juga terdapat menu pencarian untuk mencari data kriteria, data nilai, maupun data hasil penentuan. Dan juga terdapat menu about yang berisi tentang biodata pembuat software.

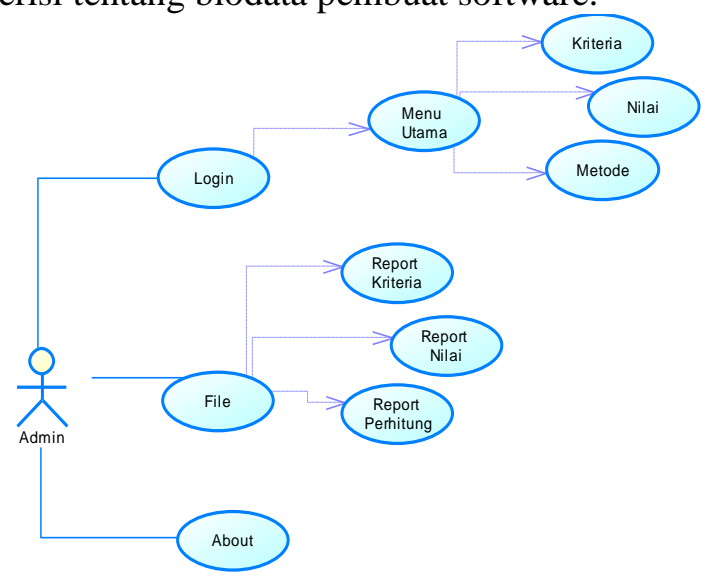

Gambar 1. Use case diagram

Gambar 2 adalah activity diagram yang menerangkan proses ketika admin akan masuk pada sistem aplikasi, maka admin harus login terlebih dahulu. Apabila login berhasil, maka aplikasi tersebut akan menampilkan halaman utama setelah login. Terdapat menu yang berisi menu kriteria, menu nilai, menu penentuan. Pada menu file terdapat report data kriteria, report data nilai, dan report data hasil. Selain itu juga terdapat menu pencarian untuk mencari data kriteria, data nilai, maupun data hasil penentuan. Dan juga terdapat menu about yang berisi tentang biodata pembuat software. Tetapi jika admin tidak berhasil login, maka admin harus kembali ke proses awal login.

Gambar 3 adalah sequence diagram menu kriteria yang menerangkan proses ketika admin akan masuk pada sistem aplikasi, maka admin harus login terlebih dahulu. Setelah itu sistem aplikasi tersebut akan menampilkan menu utama. Pada menu kriteria, user dapat melihat ataupun menginputkan data-data kriteria yang telah ditentukan sebagai penentu dalam menentukan pemberian jamkesmas. Terdapat tombol keluar jika user ingin menutup aplikasi tanpa harus kembali ke menu utama.

Gambar 4 adalah sequence diagram menu nilai yang menerangkan proses ketika admin akan masuk pada sistem aplikasi, maka admin harus login terlebih dahulu. Setelah itu sistem aplikasi tersebut akan menampilkan menu utama. Pada menu nilai, user dapat melihat ataupun menginputkan data-data kriteria yang telah ditentukan sebagai penentu dalam menentukan pemberian jamkesmas.

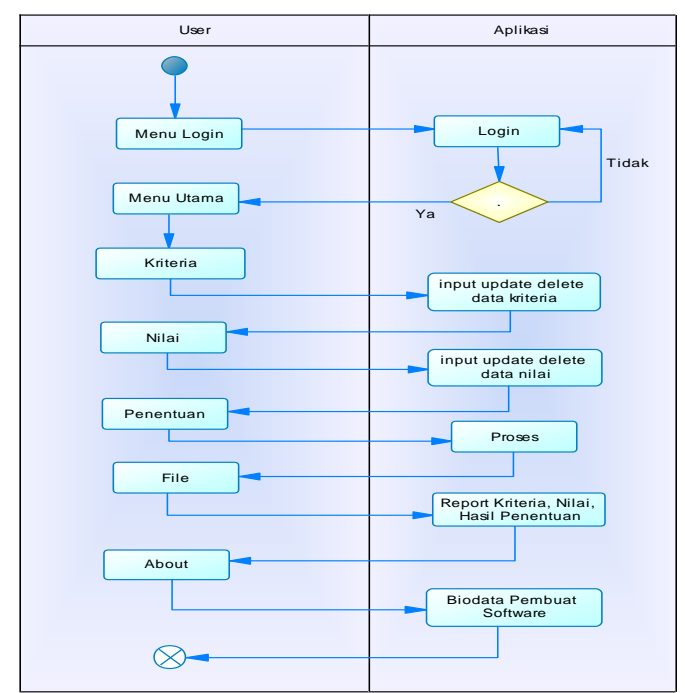

Gambar 2. Activity Diagram

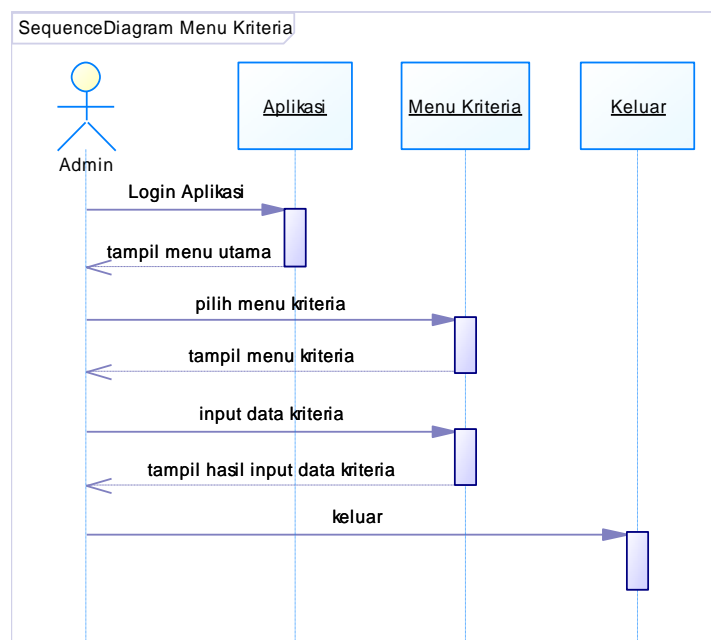

Gambar 3. Sequence Diagram Menu Kriteria

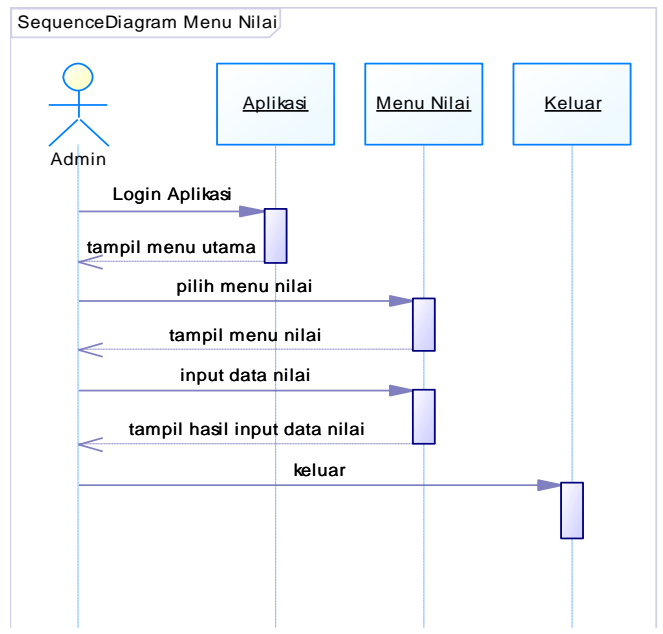

Gambar 4. Sequence Diagram Menu Nilai 
Gambar 5 adalah sequence diagram menu penentuan yang menerangkan proses ketika admin akan masuk pada sistem aplikasi, maka admin harus login terlebih dahulu. Setelah itu sistem aplikasi tersebut akan menampilkan menu utama. Pada menu penentuan, user dapat melakukan proses penentuan oleh sistem berdasarkan data kriteria dan data nilai yang sebelumnya telah diinputkan.

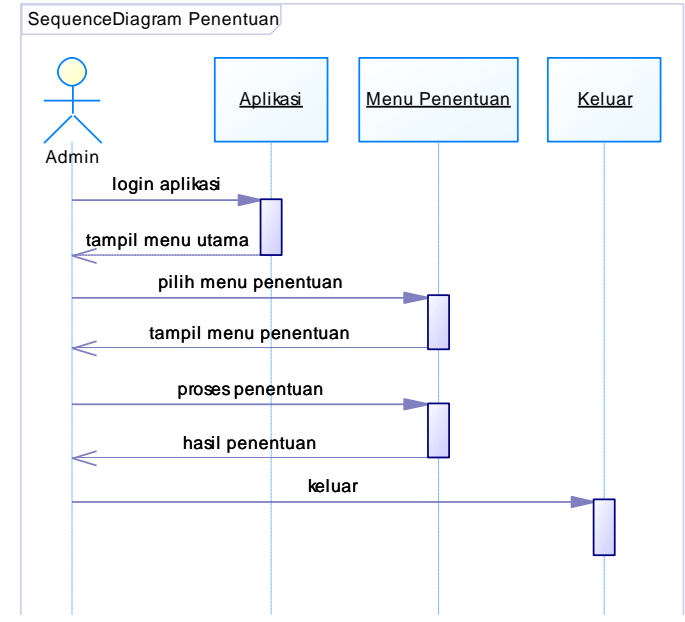

Gambar 5. Sequence Diagram Menu Penentuan

Gambar 6 adalah sequence diagram menu file yang menerangkan proses ketika admin akan masuk pada sistem aplikasi, maka admin harus login terlebih dahulu. Setelah itu sistem aplikasi tersebut akan menampilkan menu utama. Pada menu file, user dapat melihat ataupun mencetak report data kriteria, report data nilai, maupun report data hasil proses penentuan pemberian jamkesmas.

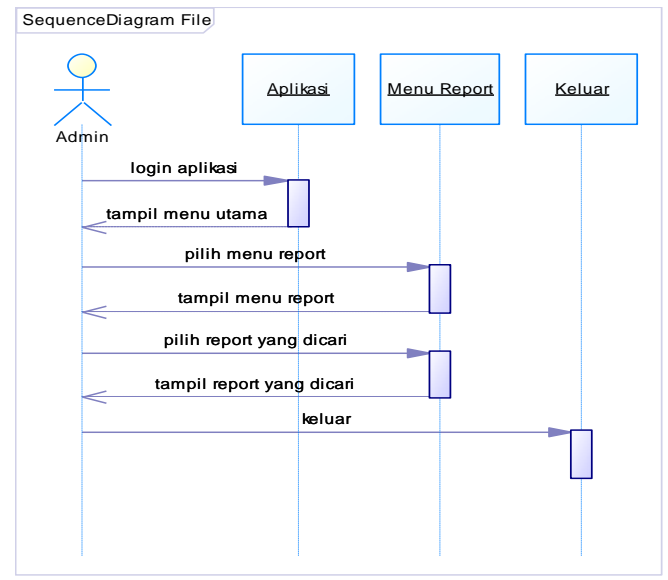

Gambar 6. Sequence Diagram Menu File
Seperti yang telah dijelaskan pada bab sebelumnya, penulis menggunakan metode fuzzy tsukamoto dengan perhitungan yang telah ditentukan. Adapun contoh proses perhitungannya adalah sebagai berikut :

\section{a. Nilai Keanggotaan (fuzzyfikasi)}

Ada 6 variabel fuzzy yang akan dimodelkan, yaitu:

1. Gaji : terdiri dari 3 himpunan, yaitu kecil, sedang dan besar. Nilai keanggotaan gaji direpresentasikan pada Gambar 7.

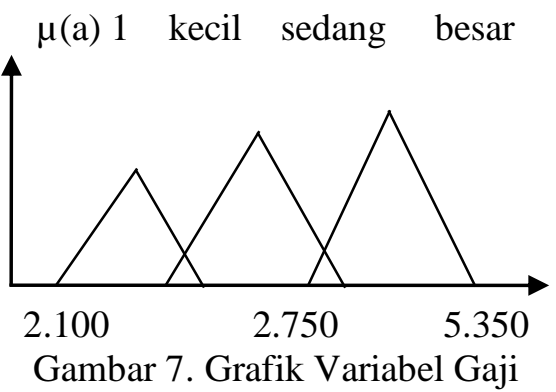

Nilai keanggotaan himpunan kecil, sedang dan besar dari variabel Gaji bisa dicari dengan:

$$
\begin{gathered}
\mu=\frac{3.000+150}{2}=1.575 \\
\mu=\frac{4.000+200}{2}=2.100 \\
\mu=\frac{5.000+500}{2}=2750 \\
\mu=\frac{10.000+750}{2}=5.350
\end{gathered}
$$

2. Pengeluaran: terdiri dari 3 himpunan, yaitu kecil, sedang dan besar. Nilai keanggotaan pengeluaran direpresentasikan pada Gambar 8 . $\mu(b) 1$ sedikit sedang banyak

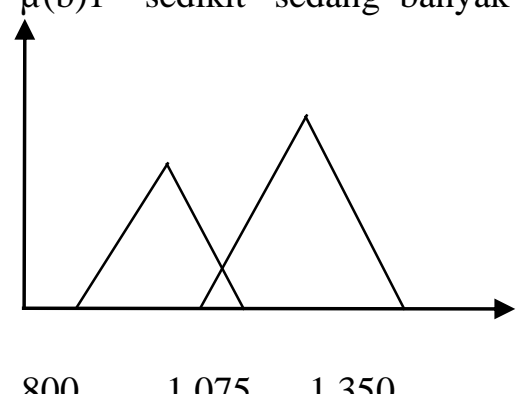

Gambar 8. Grafik Variabel Pengeluaran 
Nilai keanggotaan himpunan kecil, sedang dan besar dari variabel Pengeluaran bisa dicari dengan:

$$
\begin{aligned}
& \mu=\frac{1.500+100}{2}=800 \\
& \mu=\frac{2.000+150}{2}=1.075 \\
& \mu=\frac{3.000+150}{2}=1.575 \\
& \mu=\frac{2.500+200}{2}=1.350
\end{aligned}
$$

2. Biaya Listrik: terdiri dari 3 himpunan, yaitu kecil, sedang dan besar. Nilai keanggotaan biaya listrik direpresentasikan pada Gambar 9.

$\mu(\mathrm{c}) 1$ kecil sedang besar

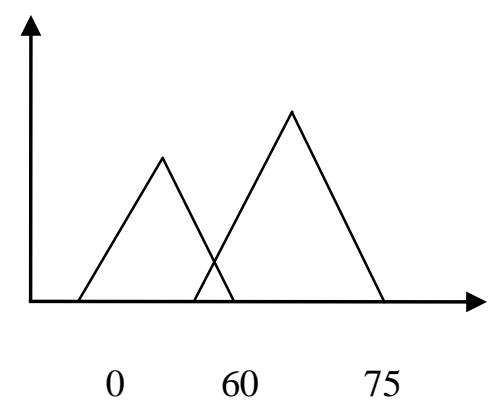

Gambar 9. Grafik Variabel Biaya Listrik

Nilai keanggotaan himpunan kecil, sedang dan besar dari variabel Biaya Listrik bisa dicari dengan:

$$
\mu=\frac{80+40}{2}=60
$$

$$
\mu=\frac{100+50}{2}=75
$$

3. Angsuran: terdiri dari 3 himpunan, yaitu kecil, sedang dan besar. Nilai keanggotaan angsuran direpresentasikan pada Gambar 10.

$\mu(d) 1$ kecil sedang besar

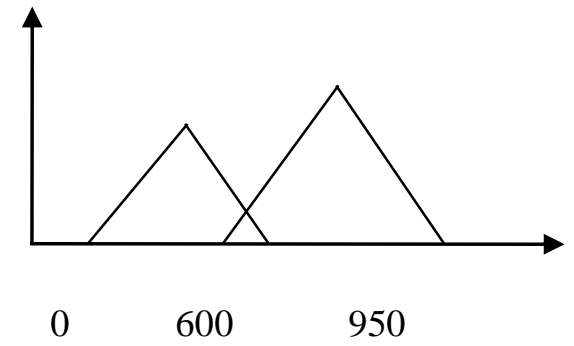

Gambar 10. Grafik Variabel Angsuran

Nilai keanggotaan himpunan kecil, sedang dan besar dari variabel Angsuran bisa dicari dengan:

$$
\mu=\frac{1.000+200}{2}=600
$$

$$
\mu=\frac{1.500+400}{2}=950
$$

4. Tanggungan: terdiri dari 3 himpunan, yaitu sedikit, sedang dan banyak. Nilai keanggotaan direpresentasikan pada Gambar 11. $\mu(\mathrm{e}) 1$ sedikit sedang banyak

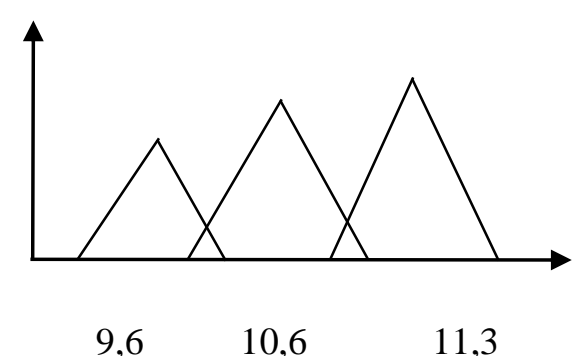

Gambar 11. Grafik Variabel Tanggungan

Nilai keanggotaan himpunan kecil, sedang dan besar dari variabel Tanggungan bisa dicari dengan:

$$
\begin{gathered}
\mu=\frac{18+10+4}{3}=10,6 \\
\mu=\frac{18+10+2}{3}=10 \\
\mu=\frac{18+10+3}{3}=10,3 \\
\mu=\frac{18+10+5}{3}=11 \\
\mu=\frac{18+10+6}{3}=11,3 \\
\mu=\frac{18+10+1}{3}=9,6
\end{gathered}
$$


5. Pendidikan: terdiri dari 4 himpunan, yaitu SD, SLTP, SMA dan S1. Nilai keanggotaan pendidikan direpresentasikan pada Gambar 12.

$\mu(f) 1 \quad$ SD $\quad$ SLTP SMA S1
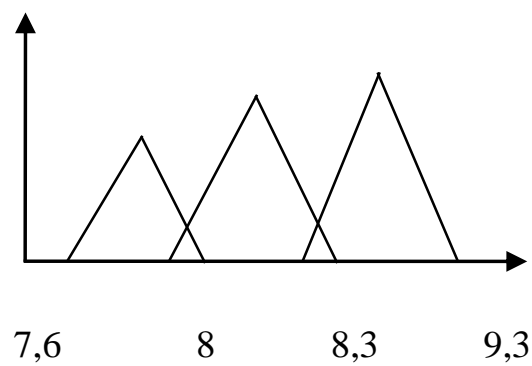

Gambar 12. Grafik Variabel Pendidikan

Nilai keanggotaan himpunan kecil, sedang dan besar dari variabel Pendidikan bisa dicari dengan:

$$
\begin{gathered}
\mu S 1=\frac{18+1+4}{3}=\frac{23}{3}=7,6 \\
\mu S M A=\frac{18+7+3}{3}=\frac{28}{3}=9,3 \\
\mu S L T P=\frac{18+4+2}{3}=\frac{24}{3}=8 \\
\mu S D=\frac{18+6+1}{3}=\frac{25}{3}=8,3
\end{gathered}
$$

\section{b. Inferensi}

[1] [Rule1] IF Gaji Kecil AND Tanggungan Sedang AND Pengeluaran Banyak AND Punya Angsuran Ya AND Biaya Listrik Sedang AND Pendidikan SD SLTP THEN Jamkesmas golongan III.

[2] [Rule2] IF Gaji Kecil AND Tanggungan Kecil AND Pengeluaran Sedang AND Punya Angsuran Tidak AND Biaya Listrik Sedikit AND Pendidikan SLTP SMA THEN Jamkesmas Golongan I.

[3] [Rule3] IF Gaji Sedang AND Tanggungan Kecil AND Pengeluaran Sedang AND Punya Angsuran Tidak AND Biaya Listrik Sedang AND SMA THEN Jamkesmas Golongan II.

[4] [Rule4] IF Gaji Besar AND Tanggungan Besar AND Pengeluaran Kecil And Punya
Angsuran Tidak And Biaya Listrik Sedang AND Pendidikan SLTP SMA THEN Jamkesmas Golongan II.

[5] [Rule5] IF Gaji Sedang AND Tanggungan Kecil AND Pengeluaran Kecil AND Punya Angsuran Tidak AND Biaya Listrik Kecil AND Pendidikan SD SMA THEN Jamkesmas Golongan III.

\section{HASIL DAN PEMBAHASAN}

Manual program adalah panduan yang disuguhkan pada pengguna agar pengguna dapat menggunakan sistem dengan baik. Berikut adalah manual program penggunaan Sistem Pendukung Keputusan Penentuan Pemberian Jamkesmas.

Halaman login merupakan halaman yang pertama kali muncul ketika Sistem Pendukung Keputusan Penentuan Pemberian Jamkesmas dibuka. Gambar 13 adalah tampilan login.

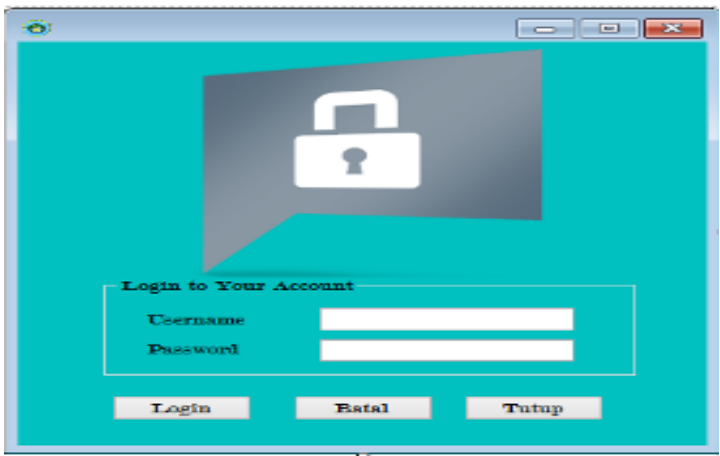

Gambar 13. Halaman Login

Berikut adalah daftar username dan password default untuk login pengguna.

\section{Admin \\ Username : admin \\ Password : admin}

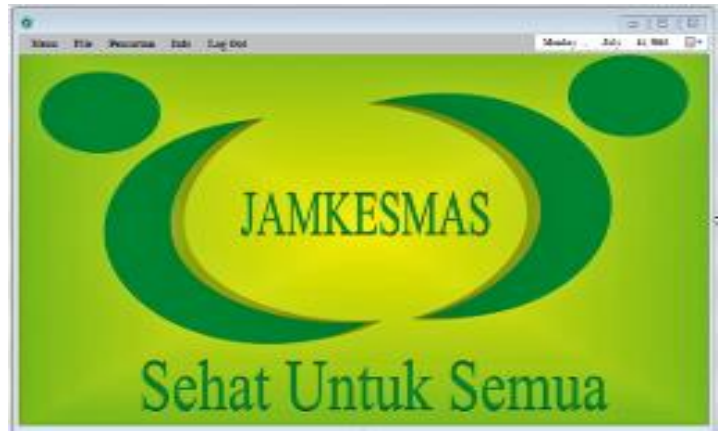

Gambar 14. Halaman Menu Utama 
Setelah admin berhasil memasukkan username dan password secara benar, maka admin akan dibawa ke menu utama. Pada menu utama terdapat beberapa tombol yang menghubungkan ke halaman-halaman yang ingin ditampilkan, juga terdapat waktu,tanggal dan area kerja yang nantinya sebagai tempat menampilkan halaman-halaman yang ingin dipanggil.

Pada halaman kriteria, user dapat menginputkan dan melihat hasil inputan kriteria-kriteria yang telah ditentukan sebagai penentu dalam menentukan pemberian jamkesmas, yaitu kriteria gaji, tanggungan, pengeluaran, asuransi, biaya listrik, tempat tinggal, dan transportasi.

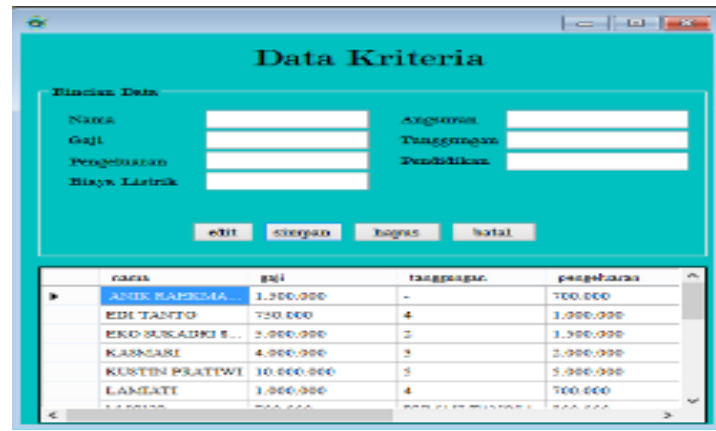

Gambar 15. Halaman Kriteria

Pada halaman nilai, pada menu nilai ini user dapat menginputkan dan melihat hasil nilainilai yang telah ditentukan sebagai penentu dalam menentukan pemberian jamkesmas seperti Gambar 16.

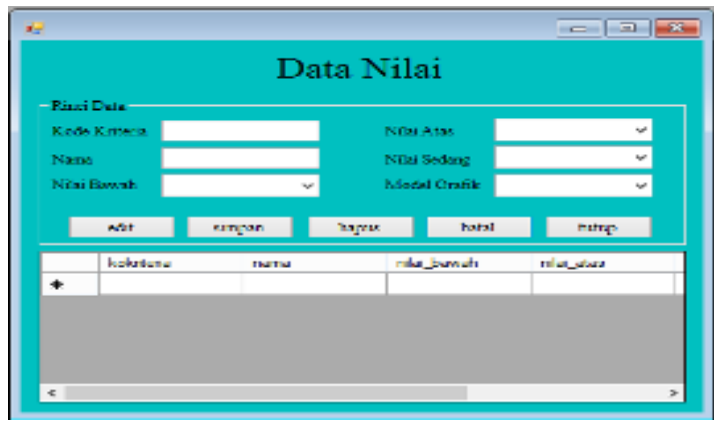

Gambar 16. Halaman Nilai

Pada menu penentuan yaitu di mana user dapat melakukan proses penentuan oleh sistem sesuai dengan kriteria dan nilai yang sebelumnya telah diinputkan untuk menentukan masyarakat bisa mendapat jaminan kesehatan masyarakat masuk dalam golongan I, II, atau golongan III seperti pada Gambar 17.

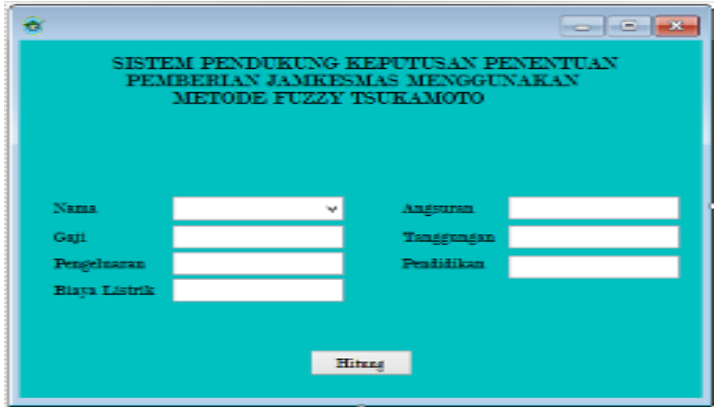

Gambar 15. Halaman Penentuan

Pada halaman report, di mana user dapat melihat file-file data nilai, data kriteria, maupun datahasil perhitungan untuk menentukan jamkesmas sesuai dengan golongannya masingmasing. Hasil tersebut nantinya dapat dicetak untuk nantinya sebagai laporan ke kepala puskesmas seperti pada Gambar 18.

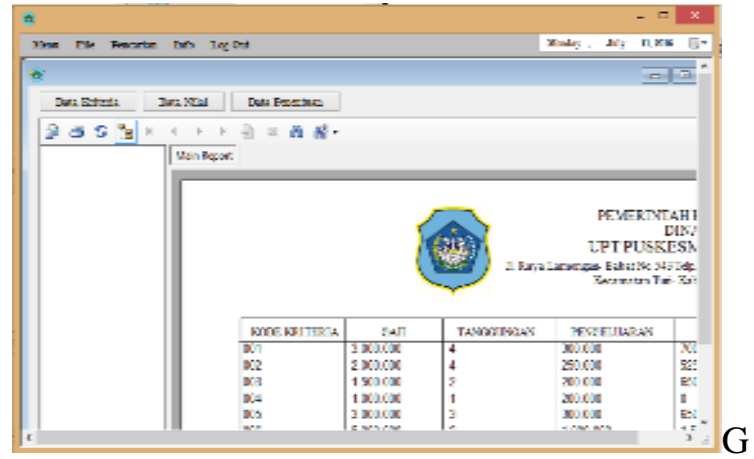

Gambar 18. Halaman Laporan

Pada menu pencarian, user dapat mencari data yang diinginkan seperti halnya data kriteria, data nilai, maupun data hasil dari proses penentuan pemberian jamkesmas seperti Gambar 19.

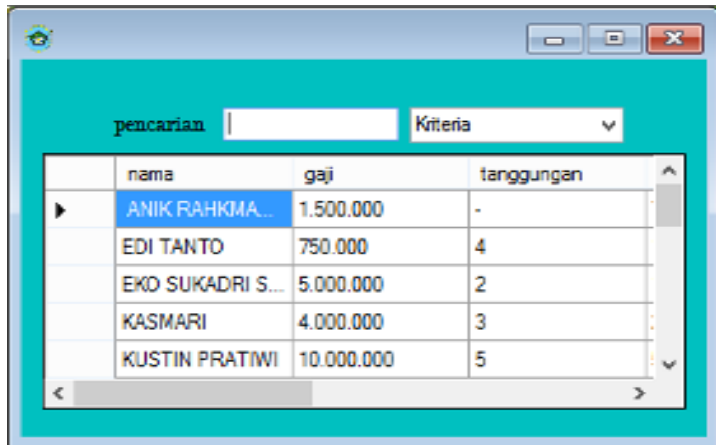

Gambar 19. Halaman Pencarian

\section{KESIMPULAN}

Setelah dilakukan uji coba perancangan Sistem Pendukung Keputusan Penentuan Pemberian Jamkesmas Menggunakan Metode Fuzzy Tsukamoto ini serta dilakukan evaluasi 
hasil penelitiannya, maka diambil kesimpulan sebagai berikut: Sistem pendukung keputusan dapat dirancang menggunakan metode fuzzy tsukamoto untuk mempermudah dalam penentuan pemberian jamkesmas. Sistem pendukung keputusan penentuan pemberian jamkesmas dapat dibuat dengan menggunakan metode fuzzy tsukamoto.

\section{REFERENSI}

[1] Ahdiyana, Marita dan Wasiti. 2013. Implementasi Program Jaminan Kesehatan Masyarakat (Jamkesmas) di Kabupaten Bantul. Yogyakarta. Tersedia Online Diakses pada http://journal.uny.ac.id/index.php/natapraja /article/download/3192/2675 (Rabu 1 Februari 2017)

[2] Ariani, Fenty and Endra, Robby Yuli. 2013. Implementation Of Fuzzy Inference System With Tsukamoto Method For Study Programme Selection. Lampung. 2nd International Conference on Engineering and Technology Development (ICETD 2013) Universitas Bandar Lampung Faculty of Engineering and Faculty of Computer Science. ISSN 2301-6590

[3] Departemen kesehatan RI, 2008, Pedoman Pelaksanaan Jaminan Kesehatan Masyarakat 2008, Departemen Kesehatan RI, Jakarta.

[4] Departemen kesehatan RI, 2011, Pedoman Pelaksanaan Jaminan Kesehatan Masyarakat 2011, Departemen Kesehatan RI, Jakarta.

[5] Rusmawan, Uus. 2013. Cara Cepat Belajar VB.Net. PT. Elex Media Komputindo. Jakarta.

[6] Turban. Efraim, Aronson. Jay E., and Ting-peng Liang. 2005. Decision Support System and Intelligent System. Andi, vol. VII. Yogyakarta.

[7] Ihsan, Ahmad. 2012. Penentuan Nominal Beasiswa yang diterima Siswa Dengan Metode Logika Fuzzy Tsukamoto. Jurnal Ilmiah Ilmu Komputer, 8(2). (Online). tersedia: (http://dspace.library.uph.edu:8080/bitstrea m/123456789/892/2/jiik-08-02-2012penentuan_nominal_beasiswa_yang.pdf), diunduh 1 Februari 2017.

[8] Farouq, Kemal. 2014. Penerapan Fuzzy Tsukamoto Dalam Pengangkatan Jabatan
Pegawai di BKD Lamongan. Jurnal Teknika, 6(2). (Online). Tersedia: (http://www.ejurnal.com/2015/11/penerapan-fuzzytsukamoto-dalam.html), diunduh 1 Februari 2017.

[9] Sri Kusumadewi \& Hari Purnomo. 2004. Aplikasi Logika Fuzzy Untuk Sistem Pendukung Keputusan Edisi Pertama. Graha Ilmu. Yogyakarta.

[10] Rakhman, A.Z.,dkk., 2012, Fuzzy Inference System Dengan Metode Tsukamoto Sebagai Pemberi Saran Pemilihan Konsentrasi (Studi Kasus: Jurusan Teknik Informatika UII), Prosiding Seminar Nasional Aplikasi Teknologi Informasi 2012 (SNATI 2012), Yogyakarta. 
Halaman ini sengaja dikosongkan 